\title{
DIMENSÕES CULTURAIS DO MARKETING: TEORIA ANTROPOLÓGICA, ETNOGRAFIA E COMPORTAMENTO DO CONSUMIDOR
}

\section{RESUMO}

O presente artigo pretende discutir a utilização da abordagem antropológica sobre o consumo e, em especial, do método etnográfico na área acadêmica de Marketing. Inicialmente serão comentados alguns textos clássicos no campo da antropologia do consumo, a fim de ressaltar a especificidade da contribuição dessa disciplina aos estudos sobre o consumo: a percepção de que esse fenômeno é, antes de tudo, simbólico e coletivo. Em seguida, são analisados os modos de utilização da etnografia nos estudos publicados em revistas acadêmicas de Marketing e na produção acadêmica de um instituto de pesquisa e ensino no Brasil. A reflexão antropológica encontrada nos estudos aqui comentados serve, em seu conjunto, para abrir novas perspectivas intelectuais, promovendo um debate crítico em relação ao viés positivista e reducionista presente no campo de investigações sobre o consumidor na área de Marketing.

\author{
Everardo Rocha \\ PUC-Rio e Coppead/UFRJ \\ Carla Barros \\ ESPM-RJ, PUC-Rio e Coppead/UFRJ
}

\begin{abstract}
The present article intends to discuss the use of the anthropological approach of the consumption and especially, the ethnographic method, in the academic area of Marketing. Initially, some classic texts in the field of Anthropology of Consumption will be commented, in order to emphasize the specificity of the contribution of that discipline to the studies about consumption - the perception that this phenomenon is, first of all, symbolic and collective. Then, we analyze the manners by which ethnography was used in the studies published in journals of Marketing and in the academic production of a research and teaching institute in Brazil. The anthropological reflection found in the studies commented here serves, as a whole, to open new intellectual prospects, promoting a critical debate concerning the positivistic and reductionistic inclination present in the field of investigations about the consumer in the area of Marketing.
\end{abstract}

PALAVRAS-CHAVE Antropologia, consumo, cultura, etnografia, comportamento do consumidor. KEYWORDS Anthropology, consumption, culture, ethnography, consumer behavior. 


\section{INTRODUÇÃO}

Existem inúmeros estudos devotados ao consumo como prática. Circulando em espaços como agências de publicidade, institutos de pesquisa de mercado ou departamentos de inteligência de marketing, essas pesquisas, que são muitas e algumas muito boas, interessam aos produtores de bens e administradores de serviços, e têm a ver, de um modo geral, com administração e vendas. É nesse circuito de empresas e negócios, exatamente no âmbito sério da produção (Rocha, 1985; Miller, 2001), que acontece a maior parte da pesquisa e se procura pensar, de alguma forma, sobre consumo.

Entrando no campo acadêmico, a abordagem antropológica do consumo - representada por autores fundamentais como Marcel Mauss (1974), Thorstein Veblen (1965), Mary Douglas (1978), Marshall Sahlins (1979) e Colin Campbell (1987), entre outros - argumenta que nem o dinheiro, nem a razão prática nem a lógica econômica explicam os diferentes significados do consumo. Uma vez que se pode pagar o preço de entrada para adquirir bens e usufruir serviços, as escolhas se tornam completamente dependentes da ordem cultural, de sistemas simbólicos e de necessidades classificatórias. O consumo apenas se reduz a um fato econômico, algo capaz de igualar a todos pela via da posse do dinheiro, até à fronteira do preço de entrada, pois a partir daí são diferenças de uma ordem mais complexa que passam a governar.

Talvez isso seja o que existe de mais questionável na chamada pesquisa de mercado que reúne consumidores em torno de classes socioeconômicas, definidas pela posse de bens de consumo e/ou renda. O erro está em reduzir a complexidade simbólica do consumo a algo que se explica apenas pelo seu preço de entrada no mercado. $\mathrm{O}$ conhecimento efetivo do consumo, como um complexo sistema cultural da sociedade contemporânea, passa por entender as diferenças simbólicas que se inscrevem a partir da equalização dos pré-requisitos econômicos supostos na compra de qualquer bem.

Produção e consumo são como textos de um repertório essencial na cultura contemporânea, que dá livre acesso ao discurso sobre compras, trabalhos, gastos e ganhos, tornando amplamente disponível para todos o imaginário que se constrói a partir dessas experiências rotineiras da vida social. Tudo isso indica que produção e consumo podem ser vistos como códigos por meio dos quais são atribuídos sentidos a um imenso conjunto de representações e práticas que ocupam um lugar central no mundo cotidiano.

O estilo de pesquisa aplicada de consumo que constitui o campo de comportamento do consumidor tem se aproximado das ciências sociais, realizando uma troca intelectual mais efetiva, como apontaram alguns levantamentos (Barros, 2002; D’Angelo, 2003; Rossi e Hor-Meyll, 2001). É o que também podemos observar em certos estudos, que, sem obrigações com resultados que se transformem imediatamente em bons negócios, demonstram a viabilidade do diálogo entre estes dois pólos - Antropologia e Marketing-, como é o caso dos livros editados por Sherry (1995), Grazia e Furlough (1996) ou Falk e Campbell (1997).

Nesse sentido, o presente trabalho deseja também chamar a atenção para uma modalidade de estudos que, cada vez mais, têm obtido espaço na área de Marketing. Estudos que se autodefinem como etnográficos têm apresentado um crescimento muito significativo no âmbito da empresa, das publicações especializadas da área (Barros, 2002), e hoje integram o portfólio de produtos de consultoria. $\mathrm{O}$ artigo começa por uma referência aos textos clássicos e, em certo sentido, criadores da perspectiva antropológica de interpretação do consumo, para em seguida mostrar estudos aplicados no exterior e no Brasil, que indicam que etnografia e interpretação antropológica se tornam uma demanda do marketing para a análise da cultura e das práticas de consumo e, mais especificamente, da área de comportamento do consumidor.

\section{FUNDAMENTOS DA ANTROPOLOGIA DO CONSUMO}

O texto que abriu a perspectiva ao tema do consumo, marcando seu lugar como algo típico da cultura do nosso tempo, foi o clássico A teoria da classe ociosa, de Veblen (1965), publicado em 1899. Esse livro possui, em primeiro lugar, a força intelectual de retirar o consumo da posição de simples efeito reflexo da produção - algo menor, portanto - e colocá-lo como fenômeno capaz de assumir um lugar destacado também como um discurso sobre as relações sociais. Veblen ultrapassou a visão utilitária do consumo que prevalece no viés economicista e deu a devida atenção ao significado cultural contido nesse fenômeno e em suas práticas. O consumo é um fato social capaz de gerar representações coletivas (Durkheim, 1970), sendo - e essa é uma intuição básica - refratário a explicações que o reduzam ao indivíduo. O consumo, inversamente, é sensível às interpretações que envolvem significados culturais e públicos. É preciso enfatizar esse ponto, pois existe uma tendência, nos estudos aplicados, para ver o consumo como algo individual. O próprio termo que designa o campo específico do Marketing - comportamento do consumidor - revela 
uma influência da corrente de psicologia behaviorista e sua ênfase no comportamento consciente e observável, reificando o indivíduo como o eixo a partir do qual se pensa o consumo.

Vale reter aqui uma idéia importante para a pesquisa do consumo e que deriva do estudo de Veblen: trata-se da intuição do consumo como indexador simbólico. Em certo sentido, pode-se dizer que Veblen aponta o lugar central do consumo como forma de comunicação. Disso deriva uma possibilidade importante: o consumo como expressão de status e como fenômeno capaz de construir uma estrutura de diferenças. Séries de produtos e serviços se articulam, pelo consumo, a séries de pessoas, grupos sociais, estilos de vida, gostos, perspectivas e desejos que nos envolvem a todos num permanente sistema de comunicação de poder e prestígio na vida social.

Outra referência igualmente importante é o clássico de Marcel Mauss, Ensaio sobre a dádiva (1974), publicado em 1923. Esse texto permite pensar a presença da ordem cultural como decisiva nas situações de troca, relativizando a prevalência do viés utilitarista e da razão prática. As trocas são fenômenos coletivos, e a circulação da riqueza é apenas um dos termos dentro do contrato amplo e permanente entre os envolvidos. As trocas respondem a necessidades culturais e não apenas econômicas, como retribuição, honra, prestígio, poder e, principalmente, o dar e o receber como obrigação da própria troca, pois a recusa do jogo das trocas significa negar a aliança e a comunhão.

Pensando na especificidade da sociedade ocidental, Sahlins (1979) oferece uma contribuição fundamental ao debate evidenciando o código cultural de propriedades concretas que governa a utilidade das mercadorias, já que em nosso ambiente fica a impressão de que "a produção não passa de um precipitado de uma racionalidade esclarecida" (1979, p. 186). A forma de pensar do economista sintetizaria o modo como a sociedade burguesa se reconhece: uma sociedade utilitarista, guiada pelo princípio da maximização material. Sahlins ressalta, assim, a especificidade da sociedade ocidental ao eleger o econômico como o lócus privilegiado de produção simbólica. A visão ocidental burguesa, que privilegia o homem econômico e concebe a sociedade como o resultado formal da ação pragmática dos indivíduos, é recente, como já havia indicado Mauss. A análise de Sahlins faz os objetos e bens pragmáticos e utilitários mergulharem definitivamente no universo dos sistemas simbólicos culturalmente constituídos. A produção deixa de ser vista como uma prática lógica de eficiência material, e se insere no reino da intenção cultural.

O paralelismo entre natureza/cultura e produção/con- sumo foi também analisado no livro Magia e capitalismo (Rocha, 1985). Nessa obra foi discutida a possibilidade - depois retomada em outro trabalho (Rocha, 1995) - de que na sociedade ocidental moderna o lugar de sistema totêmico - código que converte mensagens entre natureza e cultura - é ocupado pela mídia e, particularmente, pela publicidade, que converte as mensagens entre produção e consumo. Dessa forma, a esfera da produção precisa ser revestida dos símbolos que vão lhe dar sentido. E o consumo é a arena onde, efetivamente, esse sentido ocorre. A esfera da produção, sem atribuição de significados, é a esfera da falta que coloca na disjunção as palavras (significado) e as coisas (produtos e serviços). Introduzir o significado na esfera da produção quer dizer criar um código que faça daí nascer o consumo. A produção apenas cumpre o seu destino de ser consumo por meio de um sistema que lhe atribui significação, permitindo participar de um idioma e expressar-se numa linguagem. O consumo é, portanto, o sistema que classifica bens e identidades, coisas e pessoas, diferenças e semelhanças na vida social contemporânea.

O potencial dessas idéias e suas possibilidades para o entendimento do consumo devem ser ainda mais aprofundados. O projeto de investigar a relação entre consumo e cultura pode se beneficiar muito de certas pistas deixadas pelos textos aqui abordados. As indicações inspiradas nos trabalhos clássicos de Veblen e Mauss, adicionadas à contribuição fundamental de Sahlins, permitem interpretações consistentes do fenômeno do consumo. E também são esses clássicos que realizam uma interlocução capaz de integrar as reflexões de outros antropólogos - como Campbell (1987), Douglas (1978) e McCrakcken (1988) - nesse esforço de pesquisa sobre o complexo simbolismo implicado no consumo.

\section{ETNOGRAFIA E MARKETING: ESTUDOS EM REVISTAS ACADÊMICAS}

O que foi exposto até agora incita a pensar que esses estudos, que são referência para a área de antropologia do consumo, abrem uma boa perspectiva para a compreensão desse fenômeno. Para avançar na discussão, existe ainda outro ponto que deve ser agora analisado. Trata-se de uma perspectiva, também retirada da tradição antropológica, para decifrar representações das práticas de consumo: a etnografia.

A etnografia é um método dotado de grande tradição na antropologia e cujo desejo é realizar a descrição dos significados que um determinado grupo atribui às suas experiências de vida $\mathrm{O}$ método tem características específi- 
cas, com implicações teóricas e práticas importantes, quais sejam: ênfase na exploração da natureza de um fenômeno social particular; entrevistas em profundidade; observação participante; investigação em detalhe; perspectiva microscópica; e interpretação de significados e práticas sociais como expressos nos discursos dos informantes. Acima de tudo, e talvez esteja aí a transformação teórica mais radical que o método produziu, o que marca a etnografia é investigar por dentro a realidade de um grupo, sendo o saber gerado a partir do ponto de vista do outro.

Grosso modo, pode-se falar das diferentes tradições que marcaram a aplicação do método na antropologia. A etnografia teve, na sociedade dita primitiva, seu espaço inaugural de experimentação com Malinowski, que, de forma pioneira, conviveu, no início do século XX, com tribos das ilhas Trobriand. A experiência originou o clássico Os argonautas do Pacífico ocidental (1984), consolidando definitivamente a etnografia como prática de pesquisa em antropologia. Um segundo espaço de aplicação do método começou a se firmar a partir da chamada Escola de Chicago, com o estudo no contexto urbano da sociedade industrial, em metrópoles cada vez mais complexas. Entre os antropólogos que estudaram comunidades urbanas, destaca-se William Foote Whyte (2005), com seu estudo sobre os ítalo-americanos de Boston, nos anos 1940, introduzindo a idéia de observação participante ao vivenciar o cotidiano e procurar ser parte do grupo.

Uma vez aberta a trilha para o estudo de grupos urbanos e seus respectivos sistemas culturais, a etnografia abriu, irreversivelmente, seu espaço de prática. Na cidade, um sem-fim de grupos e uma multiplicidade de temas para serem explorados. Entre eles, o consumo. O ponto é que essas etnografias de consumidores aparecem muito freqüentemente em circuitos acadêmicos exteriores ao mundo dos antropólogos em sentido estrito. Assim, algumas revistas especializadas em marketing publicaram nos últimos 15 anos artigos relatando resultados da aplicação do método etnográfico no estudo de grupos ou espaços urbanos. Ao realizar esses estudos, que se autodefiniam como etnográficos, os pesquisadores fizeram também duas outras coisas muito importantes. De um lado, acabaram em geral se afastando de algumas das características requeridas na tradição antropológica, sobretudo o tempo de convivência com seus nativos. Por outro lado, acabaram também ampliando as possibilidades de aplicação da etnografia em situações mais voltadas para os interesses do mercado de pesquisas em comportamento do consumidor.

Alguns levantamentos (Barros, 2002; Rocha, 1999) já comentaram estudos etnográficos publicados em revistas acadêmicas desde então, como os de McGrath (1989) sobre uma loja de varejo, de Schouten (1991) sobre o consumo da cirurgia plástica, de Wallendorf e Arnould (1991) sobre as comemorações do Thanksgiving Day [Dia de Ação de Graças], de Celsi, Rose e Leigh (1993) sobre adeptos de atividades de lazer de alto risco, e o conhecido trabalho de Schouten e McAlexander (1995), sobre um grupo de consumidores denominados new bikers, proprietários das motocicletas Harley-Davidson.

Podemos destacar alguns outros trabalhos, exemplificando o contínuo interesse da área de Marketing pelo saber etnográfico. O uso da tatuagem como um elemento de construção de identidades foi analisado por Velliquette, Murray e Correy (1998) em um estudo que partiu de uma análise histórica do tema, para depois apresentar uma pesquisa etnográfica realizada na sociedade norteamericana, em que emergiram dois temas importantes. $\mathrm{O}$ primeiro referia-se ao que os autores chamaram de tattoo Renaissance, que vem a ser o renascimento do interesse pela tatuagem a partir do final dos anos 1950, como uma forma de expressão de individualidade numa sociedade de consumo que enfatizava a diversidade entre os sujeitos. Os novos clientes da tattoo fugiam do estereótipo de "marginalidade" dos antigos usuários e eram então formados por adolescentes e adultos da classe média, estudantes universitários, celebridades da mídia e do esporte, ajudando a formar o que os autores chamaram de new tattoo subculture. O segundo tema, diretamente ligado ao anterior, dizia respeito ao conceito de extended self, interpretando a arte corporal da tatuagem como uma extensão do conceito de self. No discurso dos informantes surgia a idéia de que a tattoo revelava na superfície da pele algo imanente ao sujeito e à sua "verdade interna", funcionando, assim, como um modo de comunicação da singularidade do indivíduo tatuado. Ao trabalhar a noção de extended self formulada por Russell Belk, os autores mostraram como os objetos de consumo eram expressões e extensões da subjetividade dos atores sociais, podendo simbolizar pertencimento a determinado grupo, interesses, atividades, fases da vida, realizações ou valores da subcultura tattoo. Por fim, os autores fizeram referência à idéia de simulação formulada por Jean Baudrillard, para analisar o uso de tatuagens com logos de marcas famosas, mostrando, nesse caso, uma absoluta identificação entre símbolo e indivíduo. Nesse novo contexto, os símbolos não mais representam a pessoa, eles se transformam na pessoa, como mostram os informantes que se tatuam com símbolos de marcas famosas ou de ícones do imaginário da mídia de massa.

Oswald (1999) realizou uma pesquisa etnográfica sobre 
uma extensa família haitiana que residia em uma cidade do Meio-Oeste norte-americano. O estudo mostrou de que modo os imigrantes "trocavam" de cultura por meio do uso dos bens, produtos, serviços e marcas. Os objetos de consumo permitiam que se movessem de uma identidade cultural para outra negociando suas relações entre as culturas de origem e a norte-americana. O aspecto multicultural analisado na etnografia revela a construção de uma identidade conjunta haitiana e americana, aparecendo claramente no consumo alimentar, onde pratos americanos, pratos étnicos e fast food são produzidos de acordo com a situação. O cardápio do Thanksgiving, por exemplo, abriga uma combinação que reúne o tradicional peru norte-americano, alimentos de influência francesa e de origem haitiana. O estudo mostra como o consumo de alimento se torna um veículo para adaptação da nova cultura ao mesmo tempo em que se valoriza a tradição do lar original e as idiossincrasias dos membros da família. Cada membro vive sua etnicidade de forma diferenciada, construindo sua identidade via consumo ao alternar o uso de bens de acordo com os relacionamentos cotidianos. Os consumidores étnicos pesquisados trocam referências culturais - como mostra a presença conjunta das referências norte-americana, francesa e haitiana - se movendo em mundos múltiplos que não se fundem numa única identidade homogênea e dominante.

Já a etnografia realizada por Kozinets (2001) examinou a construção de significados em subculturas de consumo que se formam na interação com os meios de comunicação. O estudo analisou especificamente os trekkies, devotos da série cult de ficção científica Star Trek (Jornada nas estrelas, no Brasil) da televisão norte-americana. Os resultados da pesquisa, realizada em fãs-clubes, em convenções e no contato com grupos da Internet, apontaram para um sistema Star Trek de objetos e imagens que, por um lado, consistem num poderoso mito sobre um refúgio utópico e sacralizado onde a aceitação da diferença é a principal regra e, por outro, servem como meio privilegiado para a construção de identidades e relacionamentos. Dentro do grande grupo de fãs do seriado, existem inúmeros grupos menores, o que mostra um processo de diferenciação instaurado entre eles, em um nível micro, a partir de práticas de consumo distintas. Há os fanáticos por jogos eletrônicos, os que exploram os aspectos científicos da série, os que fazem uma leitura subliminar dos programas como um espaço de apoio à causa gay, os que enfatizam aspectos filosóficos ou religiosos dos seriados, os que manifestam interesse pelo seu lado militarista, e assim por diante. $\mathrm{O}$ trabalho mostrou ainda a idéia, entre os informantes, de controlar o consumo relativo à série distanciando-se do que qualificam como comercialização excessiva. Esse desejo de controle sobre a dimensão comercial da série leva, na interpretação do autor, ao paradoxo de acabar legitimando posteriormente outra forma particular e talvez maior de consumo.

Ao lado dos estudos que apresentaram a realização de pesquisas etnográficas, houve um significativo espaço nas revistas acadêmicas de Marketing para artigos que discutiram a própria possibilidade de utilização do método etnográfico na área de pesquisas sobre o consumidor (Barros, 2002). Aqui temos uma tentativa de legitimação desse método como um inovador modo de entendimento dos significados do consumo. Esses artigos, desde a publicação pioneira de Sherry (1989), se constituíram em importante referência para outros trabalhos teóricos e práticos que viriam a seguir. Os autores fazem críticas, de modo geral, aos métodos artificiais ou de laboratório, inclusive àqueles amplamente utilizados em pesquisas de mercado, e que acabariam por fornecer uma visão esquemática e parcial do comportamento do consumidor. Segundo esses autores, a etnografia, por acompanhar o dia-a-dia dos pesquisados em seu hábitat natural, procurando identificar os mecanismos simbólicos que orientam as ações relativas ao consumo, proporcionaria uma visão mais complexa do universo pesquisado.

Mais recentemente, Elliott e Jankel-Elliott (2003) discutiram como o método etnográfico pode ser útil para a compreensão profunda da "experiência viva" dos consumidores. Os autores comentam que estaria havendo um crescente interesse na área de Marketing por métodos de pesquisa criados nos diversos campos de estudos das ciências sociais, inclusive na etnografia, que daria acesso ao entendimento do consumidor como um ser social. Inicialmente, os autores abordam os pressupostos básicos do método etnográfico, quais sejam: o estudo do comportamento social no mundo real; a crença de que não há como apreender esse comportamento sem entender o mundo simbólico dos sujeitos, alcançando seus pontos de vista e tendo contato com os significados compartilhados em grupo e expressos na linguagem da vida cotidiana; a imersão em um trabalho de campo de longa duração, que aumenta a possibilidade de entrar em contato com momentos importantes do dia-a-dia dos informantes, bem como com incidentes reveladores; a busca da compreensão das regras locais que orientam a visão de mundo dos atores sociais. $\mathrm{O}$ artigo aborda ainda os aspectos práticos do método. Estes incluem os níveis de envolvimento nos diversos modos de observação participante, a adaptação para o campo dos negócios de um tempo de imersão em campo mais reduzido do que o usual em etnografia e a 
utilização de entrevistas formais, informais, diários de informantes e do pesquisador como instrumentos de coleta de dados. O uso do método antropológico na área de pesquisa de Marketing, que recebe aqui a denominação de quasi-ethnography [quase-etnografia] ou commercial ethnography [etnografia comercial], é então analisado mais detalhadamente, mostrando de que modo foram feitas adaptações que tornaram possível sua utilização. A grande preocupação, nesse caso, foi desenvolver técnicas de pesquisa que reduzissem o tempo de permanência no campo, sem abrir mão dos outros pressupostos do método etnográfico e da abordagem antropológica sobre o comportamento social.

Cabe aqui ressaltar que a questão do tempo em campo deveria ser tratada com cuidado, por estar ligada a um dos aspectos mais importantes do método antropológico. A etnografia foi pensada a partir da idéia de que o contato prolongado com um determinado grupo propicia o acesso às múltiplas camadas dos fenômenos sociais (LabourtheTolra e Warnier, 1997). As adaptações do método deveriam ser feitas chamando-se a atenção para as possíveis perdas decorrentes de determinados caminhos escolhidos. O tipo de dado gerado no trabalho etnográfico é diferenciado, entre outros aspectos, por permitir que a complexidade dos comportamentos sociais seja revelada dentro do tempo do grupo estudado.

\section{ETNOGRAFIA E MARKETING: INVENTARIANDO UMA DETERMINADA PRODUÇÃO BRASILEIRA}

O uso do método etnográfico na área de pesquisa em Administração no Brasil ainda é recente, com trabalhos registrados na área de cultura organizacional e outros no campo do consumo. Nesse último campo, será feita uma análise dos estudos desenvolvidos no projeto acadêmico do Instituto Coppead de Administração - UFRJ, por ter sido o primeiro programa de pós-graduação do país a criar dentro da área de Marketing uma linha de pesquisa em antropologia do consumo. Até o final do ano de 2003, foram defendidas dez dissertações de mestrado, que têm em comum a proposta de compreensão da dimensão cultural presente nos comportamentos de consumo de determinados grupos sociais urbanos. Essas dissertações objetivam explorar, por meio da aplicação de princípios do método etnográfico, uma perspectiva concreta de análise cultural, captando imagens, representações, estilos, práticas e valores relacionados ao universo do consumo tal como vividos por determinados grupos de consumidores. Esses estudos se propõem, portanto, entender a visão que grupos bem definidos de camadas médias urbanas têm do consumo e examinar o peso relativo que esse fenômeno adquire em suas vidas. Numa palavra, conhecer "por dentro" o imaginário e as práticas desses grupos entendendo como vivenciam suas respectivas experiências de consumo.

O primeiro estudo nessa linha de pesquisa foi o realizado por Carvalho (1997), e procurou compreender o simbolismo de objetos de decoração para jovens casais da classe média do Rio de Janeiro, casados há pouco tempo e sem filhos. Os principais temas emergentes da análise do discurso foram interpretados a partir da compreensão de algumas categorias. O primeiro deles foi o individualismo, elemento característico e fundador das sociedades modernas, conforme a análise seminal feita por Dumont (1972). No espaço da casa ficou evidenciada a necessidade de que lá estivessem refletidos as preferências estéticas e os gostos pessoais dos ocupantes, ou seja, sua identidade. A personalidade do morador deve estar materializada na decoração, que espelharia seu jeito de ser, evitando modismos massificadores. Essa personalização da residência tem como um de seus principais caminhos a diferenciação. Procura-se construir um espaço único e distinto, que seja diferenciado pela sua originalidade de qualquer outro ambiente, evidenciando assim a singularidade casa-morador. O segundo tema analisado na pesquisa refere-se ao domínio masculino e feminino. Na experiência do grupo, os homens participam ativamente das atividades relacionadas à decoração da casa, embora ainda caiba às mulheres uma maior responsabilidade nas decisões de compras. O hedonismo aparece como o terceiro tema interpretado, expressando uma busca de prazer físico e mental dentro do universo aconchegante e íntimo da casa. Esse espaço se contrapõe, assim, ao mundo público, confuso e hostil. O refúgio do lar deve ser preservado e distanciado da realidade lá de fora, se constituindo em um ambiente completo e autosuficiente, composto de objetos confortáveis.

Em outro estudo, Kubota (1999) procurou compreender a lógica de consumo de um grupo de pessoas de terceira idade da classe média alta, residentes na Zona Sul do Rio de Janeiro. A pesquisa enfatizou a investigação sobre o consumo relacionado com o hedonismo, como lazer e entretenimento, sem se deter especificamente na aquisição de bens e serviços ligados ao atendimento de necessidades mais básicas, como alimentação e consultas médicas. O primeiro tema emergente do discurso dos aposentados está relacionado à dicotomia casa e rua, seguindo a definição de DaMatta (1985). Partindo do pressuposto de que estamos inseridos em uma sociedade profundamente relacional, o autor mostra a importância da troca de bens dentro da rede de parentesco, compadrio e ami- 
zade. Analisando as diferenças de gênero em relação ao consumo na terceira idade, Kubota nota que as mulheres tendem a ser mais ativas na procura de lazer e cursos de atualização, enquanto os homens se "feminilizam" - ou se "acomodam", segundo o discurso dos informantes -, já que passam a dedicar mais tempo ao espaço da casa. $\mathrm{O}$ segundo tema trata da diferença entre gerações, mostrando que as gerações passadas concebiam a aposentadoria como uma fase de inatividade e decadência, enquanto para os informantes trata-se de uma etapa da vida potencialmente produtiva e prazerosa, em que estão presentes valores como motivação, atualização e diversão.

Outro estudo, de Bellia (2000), investigou a lógica de consumo de um grupo de jovens moradores da Barra da Tijuca, bairro da Zona Oeste do Rio de Janeiro - os novos ricos cariocas, membros de famílias que alcançaram a riqueza por meio do sucesso na vida profissional, e não por herança ou casamento. A autora mostra como o grupo estabelece a distinção entre o que é "ser brega" e "ter bom gosto" ou "personalidade própria" a partir de uma crítica aos modismos, especialmente aos relacionados ao vestuário. Utilizando-se dos conceitos de seguidores (os que aderem a qualquer modismo) e esnobes (os que querem ser inovadores em termos de consumo) analisados por Veblen, Bellia mostra o aparente paradoxo do grupo que quer se distinguir dos seguidores (consumidores do estilo brega) adotando um modo de vestir comum - o básico -, que expressa normalmente uma renúncia a qualquer singularidade. O estudo com jovens moradores da Barra da Tijuca também revela uma grande influência da família - influência denominada pela autora fator hereditário ou fator linhagem - no processo de socialização para o consumo, pois os informantes valorizam as marcas utilizadas e presenteadas pelos pais, caracterizadas como tradicionais e de qualidade. O estudo mostra que o grande esquema classificatório proporcionado pelo consumo opera em vários níveis, definindo oposições como "ser brega" e "ter personalidade própria" ou "ser morador da Barra" e "ser morador da Tijuca", que são associadas a objetos, serviços, comportamentos e estilos de vida.

O trabalho de Ouchi (2000) investigou o consumo de adolescentes vestibulandos de um colégio tradicional freqüentado pela elite da cidade de Juiz de Fora, em Minas Gerais. O primeiro tema abordado na análise diz respeito à própria idéia de consumo. Para os vestibulandos, o consumo relacionado ao atendimento de necessidades básicas seria uma ocupação dos pais, enquanto o seu mundo de consumo particular estava associado à idéia de insaciabilidade, que fazia com que os produtos fossem constantemente substituídos por novos objetos de desejo.
A pesquisa identificou a influência do meio social no comportamento do consumo como o tema mais importante no discurso dos informantes. Esse tema foi abordado em dois aspectos: a diferença entre consumo público e privado, e a competição na busca de diferenciação social. Referindose aos conceitos de casa e rua utilizados por DaMatta (1985) em suas análises sobre a sociedade brasileira, a autora mostra como opera no universo dos adolescentes a distinção entre consumo público e privado, sendo o primeiro percebido como uma espécie de obrigação (como as leis do mundo da rua) que tem que ser cumprida para se manter o status adquirido, mas que impede a pessoa de ser o que ela realmente é. A importância do chamado grupo de referência é aqui fundamental, revelando primordialmente a necessidade de ser aceito pelos pares e de manter seu lugar conquistado dentro do grupo. A noção de conformidade à vontade do grupo está presente de modo bastante claro e consciente, evidenciando o valor, para os adolescentes, de se igualarem aos outros para obterem a aprovação do grupo. Um segundo aspecto relacionado ao tema da influência do meio social refere-se ao consumo conspícuo dos adolescentes pesquisados. Para o grupo, o uso de bens de marcas e grifes de status reconhecido comunica de forma incontestável a força pecuniária do seu possuidor, proporcionando diferenciação e prestígio social, como já mostrara Veblen (1965).

Ballvé (2000) procurou pesquisar em seu estudo o fenômeno do consumo no universo de um grupo de crianças de classe média de uma escola particular na Zona Sul do Rio de Janeiro. No primeiro tema abordado, a consciência da idade, as crianças mostram uma forte percepção de sua inserção em determinado estágio da vida - a infância - e das atitudes, rituais e comportamentos adequados para cada um dos momentos dessa etapa etária. Assim, determinados produtos, lojas, marcas e programas de TV são percebidos como mais adequados que outros para o consumo dentro da sua faixa etária. Seguindo a análise, o segundo tema investigado aborda a questão da construção da auto-imagem, onde se discute a grande influência dos pais e da mídia na formação da personalidade da criança. No tema seguinte, denominado mídia e informação, essa questão é aprofundada, quando se mostra o papel fundamental da mídia na criação de uma linguagem própria para as crianças. O quarto tema, instantaneidade, explora um determinado aspecto da lógica infantil: um grande desejo daquilo que muda, de novidade. Essa insaciedade e gosto por modismos encontram expressão em diversos campos, como nas escolhas dos programas de TV e dos lugares de lazer. Analisando o quinto tema, a autora aborda a questão da posse de um bem do ponto de vista infantil, 
enfatizando como a posse se torna praticamente um prérequisito para gostar de um bem. O objeto que passa a fazer parte da vida da criança se personaliza ao transferir suas características àquela determinada pessoa, tornando-se parte integrante de sua história particular, até ser substituído por outra novidade. A análise do sexto e último tema, consumo e estratégias econômicas, revela como as crianças constroem um senso estético que determina o que é de "bom gosto" ou não, habilitando-as a julgar, com desenvoltura, o valor dos produtos dos meios de comunicação de massa e de consumo em geral. Em relação à influência das crianças sobre o consumo familiar, o estudo analisa as estratégias econômicas que elas utilizam para obter o que desejam. As estratégias seguidas mostram as crianças como hábeis negociadoras, que sabem discutir preços e valores com naturalidade e obter os itens desejados a partir de articulados argumentos de convencimento. Estabelecem parcerias bem-sucedidas com os pais, o que leva a autora a concluir que elas assumem um verdadeiro papel de businessman em relação ao consumo.

Blajberg (2001) realizou outro estudo que buscou a compreensão dos padrões de consumo de homens judeus casados e bem-sucedidos financeiramente e moradores do Rio de Janeiro. A pesquisa buscou investigar de que modo se estabelecia o aparente paradoxo entre os movimentos de globalização e tribalização, na medida em que eles compartilhavam de um sentimento de identidade étnica dentro de um mundo marcado pela fragmentação de identidades globais. Um primeiro tema analisado foi o da definição de consumo para os informantes. Essa atividade era vista como voltada basicamente para a família, e não para a própria pessoa. $\mathrm{O}$ estudo mostrou que o grupo compartilhava da idéia de consumo temporal, que é um modo de definir formas de consumo, classificando-as em função do tempo. Assim, um primeiro modo de conceber essa atividade seria como um investimento, visando o longo prazo, e um segundo, como uma despesa, que atenderia a necessidades de curto prazo, consideradas como básicas e de subsistência. O consumo de longo prazo se volta para os investimentos que garantiriam à família segurança para sobreviver com tranqüilidade no futuro. As opções de investimento mostram uma aversão ao risco e uma procura da estabilidade, mais do que o retorno pelas aplicações em si.

Surge então a questão da prudência e do planejamento em relação ao futuro. Esse resguardo se expressa nessa forma de consumo, em que a construção de um patrimônio a ser partilhado posteriormente simboliza a própria continuidade do núcleo familiar, garantida graças à ação preventiva e calculada dos chefes de família. Outro tema abordado no trabalho foi o relativo ao consumo étnico. Os serviços de natureza judaica foram citados com maior freqüência do que os produtos, por serem mais diretamente relacionados aos ritos de passagem e eventos sociais. Tais acontecimentos, como o Brit-Milá, o Bar ou Bat-Mitzvá e o casamento judaico, são de extrema importância para os informantes inserirem a si próprios e seus familiares num ambiente judaico. Os padrões de consumo, ao mesmo tempo em que permitem a construção de sua auto-imagem, alimentam o forte sentimento de coesão do grupo.

O estudo de Soares (2002) procurou compreender a percepção que um grupo de profissionais liberais negros bem-sucedidos, integrantes da classe média alta, tem em relação a seu próprio estilo de consumo. Um primeiro aspecto evidenciado na pesquisa refere-se à própria idéia do consumo como uma atividade a ser permanentemente controlada. Os informantes fazem uma distinção entre o consumo de bens que atenderiam às suas necessidades básicas - como alimentação, vestuário, locomoção - e outro tipo de comportamento impulsivo relacionado à compra de bens supérfluos, denominado consumismo. Ao mesmo tempo em que ressalta o lado negativo dessa última forma, afirmam que adquirir bens não essenciais faz parte de um processo natural e inevitável de diferenciação social, ao qual são forçados a aderir, mas que também proporcionaria pequenos prazeres. Na visão do grupo, o vestuário aparece como um meio fundamental de dar visibilidade à ascensão social experimentada por todos eles. Na busca do reconhecimento do status adquirido, consideram importante cuidar bem da higiene pessoal, freqüentar bons restaurantes, cozinhar pratos especiais em casa e consumir bebidas com um nível de qualidade compatível com o espaço social alcançado. Esse esforço por reconhecimento social caminha ao lado da percepção de sua invisibilidade no mundo do consumo. Apesar da constatação de uma relativa mudança nesse aspecto nos últimos tempos, o grupo compartilha do sentimento de que o homem negro bem-sucedido é como um ente invisível, ainda pouco representado e atendido no mundo da propaganda, da mídia e dos produtos disponíveis no mercado.

O trabalho de Ferreira (2002) procurou compreender o significado do consumo para um grupo de mulheres separadas, residentes no Rio de Janeiro e bem-sucedidas profissionalmente. O primeiro dos temas emergentes na pesquisa dizia respeito ao próprio sentido do consumo. As informantes estabelecem, em primeiro lugar, uma clara distinção entre os gastos ordinários, relacionados às despesas domésticas, vistos como uma obrigação, e os gastos com coisas pessoais e atividades de lazer - associados ao prazer, à diversão e à própria idéia de consumo em si. 
Outro grande tema emergente do trabalho refere-se ao vínculo entre consumo e separação. O consumo passa a ser, após a separação, um meio privilegiado de recuperação da auto-estima das informantes, graças à sua capacidade de proporcionar prazer. Ao se cuidarem mais, as mulheres separadas se afastam da dor causada pela separação consumindo terapeuticamente o que as faça sentirem-se mais bonitas e autoconfiantes. Então surge a ênfase na utilização do consumo como meio de expressão da individualidade. Após a separação, decisões de reformar o próprio quarto, de comprar um vestido especial dentro de um estilo nunca usado no tempo de casada, viabiliza o aparecimento de outro eu, recuperado ou totalmente novo. O consumo, por um lado, realiza a expressão de desejos antes ocultos, em um movimento de dentro para fora, e por outro, serve como apoio ao processo de recuperação do eu, por meio de um movimento de fora para dentro, livre da antiga subordinação aos planos do casal. Essa valorização da soberania individual no campo das decisões do consumo põe em destaque o resgate da individualidade e da satisfação em consumir para si própria, revelando um aspecto positivo, de ganho, adquirido após a separação.

O estudo de Silveira (2002) se deteve sobre a lógica de consumo de yuppies residentes na cidade do Rio de Janeiro, todos jovens profissionais bem-sucedidos do mercado financeiro. A pesquisa de campo conduzida resultou na identificação de seis temas centrais: vida profissional e acadêmica, individualismo, preocupação com a aparência, hábitos de consumo, importância atribuída às marcas e materialismo. O primeiro desses temas evidenciou um aspecto comum na trajetória de vida dos pesquisados: sua história de sucesso econômico não estava vinculada a uma herança familiar, mas sim ao resultado de seu próprio trabalho e esforço pessoal. O individualismo apareceu como um segundo tema importante, presente especialmente no ambiente de trabalho nos bancos, marcado por uma grande competitividade, já que uma parte significativa da remuneração dos yuppies é atrelada a uma boa performance individual. Um terceiro tema emergente na pesquisa foi o relacionado à preocupação com a aparência, mostrando a influência do grupo de referência nas escolhas de consumo e na procura de se vestir em conformidade com o ambiente social freqüentado. Outro tema analisado no trabalho foi o relativo aos hábitos de consumo do grupo. Uma característica importante observada nesse aspecto foi o gosto pela novidade, expresso, por exemplo, no alto consumo de produtos de alta tecnologia. Os yuppies, ao falarem da importância da marca na escolha de seus objetos de desejo - que chega a ser comparada a uma obra de arte -, mostram a transformação do produto desumanizado em um artigo com uma identidade particular, como já falara Rocha (1985). Por fim, o consumismo e o materialismo são tidos pelos informantes como aspectos fundamentais de sua vida, sendo o consumo percebido como uma espécie de recompensa pelo intenso trabalho do dia-a-dia. Para serem reconhecidos pela sociedade, já que não possuem um nome de família que legitime seu status, praticam o consumo conspícuo, definido por Veblen como um modo de fazer dos bens um veículo de visibilidade e posicionamento frente aos outros membros do grupo.

A pesquisa de Walther (2002) procurou analisar o comportamento de consumo das "patricinhas", termo criado para designar um segmento de meninas adolescentes e jovens, de 13 a 20 anos, pertencentes à classe alta do Rio de Janeiro, consideradas "consumidoras vorazes" de produtos e serviços associados a marcas de grande prestígio e status social. O rótulo de patricinha não é fixo, variando de acordo com o ponto de referência de quem o aplica. Ou seja, não existem atributos objetivos para se designar alguém com o termo. A análise do discurso das informantes evidenciou os temas mais importantes para a compreensão da visão de mundo do grupo.

O primeiro deles é o da auto-imagem, revelando uma constante preocupação com o modo pelo qual sua aparência externa será julgada pelos outros. O consumo, no universo das patricinhas, é vivenciado como uma atividade extremamente prazerosa e terapêutica, capaz de curar tristezas e depressões. Por um lado, o grupo concebe sua forma de consumo como distante da satisfação de necessidades, pelo seu caráter supérfluo e prazeroso; por outro, a aquisição de bens de luxo é percebida como um tipo de necessidade imposta pela voraz luta por status na sociedade. O segundo tema, do luxo e do desejo, aborda alguns aspectos da criação do desejo de luxo no universo do grupo. As patricinhas definem o desejo de consumo como algo dominador e incontrolável, o que faz com que a compra por impulso seja uma constante em seu dia-adia. A temática do dilema e das contradições mostra, conclusivamente, que o mito da patricinha é vivenciado pelo grupo pesquisado a partir de um dilema que contrapõe o desejo do conspícuo e sua negação. As informantes, ao mesmo tempo em que querem exibir opulência por meio do uso de marcas e símbolos de status, recusam o rótulo de meninas fúteis, materialistas e mimadas, por culpa e vergonha frente à condenação a esse comportamento de consumo marcado pelo hedonismo.

Por último, o estudo de Martinez (2002) teve como objetivo a compreensão dos padrões de consumo de um grupo jovem de uma Igreja Católica do Rio de Janeiro. Os principais temas emergentes do trabalho foram: o me- 
canismo de suspensão do consumo dentro da igreja, os padrões de consumo definidores da identidade do grupo, as diferenças dentro do próprio grupo que podem ser compreendidas como grandes clãs e a percepção dos temas da produção e do consumo. Inicialmente, Martinez procura compreender o simbolismo da escolha de alguns alimentos que sempre estão presentes no cardápio dos encontros do grupo, como o macarrão parafuso com salsichas, o salgadinho Skinny e o café fraco da garrafa térmica. A simplicidade da alimentação servida expressa a procura de um nivelamento do consumo capaz de provocar a suspensão temporária das diferenças sociais dentro do grupo. Essa é a lógica da dádiva, onde se enfatiza a gratuidade de se oferecer a cada participante, em condições de igualdade, o mínimo necessário para a sobrevivência. Articula-se, dessa forma, uma contraposição entre o consumismo do mundo lá fora e a dádiva vivida aqui dentro. O discurso que se enuncia como "se eu mudei de personalidade, mudei de roupa" revela que o grupo percebe uma transição de um mundo regido pelas aparências, onde o comportamento em geral e o consumo em particular seguiam regras impostas. Se houve conversão para uma nova vida, então se libera o "verdadeiro eu", que permite às pessoas serem elas mesmas. As roupas passam a ser diferentes, novos lugares são escolhidos para o lazer, e a intensidade e os gastos com o consumo são substancialmente reduzidos. Tudo isso é expressão da conversão.

\section{COMENTÁRIOS FINAIS}

A consolidação da área de comportamento do consumidor nas universidades americanas e européias nos anos 1980 como uma disciplina essencialmente multidisciplinar abriu espaço para a aproximação de antropólogos com o ambiente acadêmico do Marketing. A reflexão antropológica encontrada nos estudos aqui comentados procurou, de um modo geral, promover a abertura de um debate capaz de relativizar o paradigma positivista e reducionista bastante presente nas investigações sobre o consumidor. A afirmação de que o consumo é, antes de tudo, um ato simbólico e coletivo promoveu um grande deslocamento nos modos dominantes de pensar esse fenômeno no universo de pesquisas em Marketing, e o debate que começou no final dos anos 1980 vem se ampliando consistentemente desde então.

Em termos da utilização do método etnográfico nas dissertações de mestrado comentadas neste artigo, alguns pontos se destacam. Todos os estudos foram conduzidos a partir da realização de entrevistas individuais em pro- fundidade, com roteiros semi-estruturados. Em alguns casos, além das entrevistas, houve uma convivência mais prolongada com o grupo, quando se procurou exercitar a tradicional observação participante, o que se traduziu em um substancial enriquecimento do material de pesquisa coletado. Os autores dos trabalhos, ao se referirem ao uso do método, falam em realizar um estudo em um estilo etnográfico, ou fazer uma adaptação da etnografia ao campo de pesquisas sobre consumo. No caso, o tempo e a forma de imersão junto ao grupo foram os principais aspectos modificados em relação à tradição de pesquisa etnográfica. As pesquisas foram realizadas durante um período mais curto do que se faria em uma etnografia tradicional, além do que, como já foi citado, nem todos os trabalhos adotaram sistematicamente a observação participante como prática de campo. Vale ressaltar que no campo da Antropologia existe muita discussão sobre o método (Clifford, 1998; Geertz, 1997; Peirano, 1995) e que, embora a observação participante tenha seu lugar de destaque, outras técnicas de pesquisa também são utilizadas. Os estudos, embora tenham perdido por não terem sido desenvolvidos a partir de uma imersão mais profunda em campo, mantiveram, por outro lado, o fio condutor dos estudos etnográficos em geral: a procura dos significados culturais que orientam o ponto de vista nativo. No caso, os trabalhos evidenciaram como o consumo nas sociedades modernas é capaz de produzir sujeitos diferenciados, criando um enorme sistema que pode ser a qualquer momento redefinido e ressignificado.

Por fim, vale acentuar alguns pontos que parecem "bons para pensar" o consumo como questão antropológica. Em primeiro lugar, o consumo é um sistema de significação, e a principal necessidade social que supre é a necessidade simbólica. Em segundo, o consumo é como um código, e por meio dele são traduzidas boa parte das nossas relações sociais e elaboradas muitas das nossas experiências de subjetividade. Em terceiro, esse código, ao traduzir sentimentos e relações sociais, forma um sistema de classificação de coisas e pessoas, produtos e serviços, indivíduos e grupos. O consumo permite um exercício de classificação do mundo que nos cerca a partir de si mesmo e, como é próprio dos códigos, pode ser sempre inclusivo. No caso do código do consumo, inclusivo em pelo menos dois sentidos. De um lado, inclusivo de novos produtos e serviços que a ele se agregam e são articulados aos demais, e de outro, inclusivo de identidades e relações sociais que são definidas, em larga medida, a partir dele.

Marketing, mídia, publicidade são intérpretes da esfera da produção, socializando para o consumo ao disponibilizar um sistema classificatório que liga um produto a cada 
outro e todos juntos às nossas experiências de vida. Esse é precisamente o projeto subjacente ao edifício de representações da vida social construído dentro da mídia: classificar a produção, criando um processo permanente de socialização para o consumo. Assim, uma especificidade da cultura moderna, algo como uma de suas singularidades históricas, reside nesse sistema de integração simbólica da diferença entre produção e consumo, por meio da distribuição de significados a partir da esfera da produção, realizando o destino de produtos e serviços na direção de mercados e consumidores. Nesse jogo de magia, mito e ritualização, acontece o consumo, instância privilegiada para realizar um exercício permanente de classificação que, ao estilo de um sistema totêmico, fornece os valores e categorias por meio dos quais concebemos diferenças e semelhanças entre objetos e seres humanos.

Algumas dessas idéias abrem possibilidades para que as pesquisas no campo do Marketing continuem se desenvolvendo na busca da captação do significado cultural do consumo. Em primeiro lugar, é importante dar continuidade ao estudo do consumo por meio da realização de etnografias de grupos de consumidores para que se obtenha um quadro mais preciso dos múltiplos códigos que ordenam essas práticas. O estudo etnográfico permite conhecer as formas como os grupos sociais atribuem significados aos produtos e serviços, dando-lhes sentido diferenciado, incluindo-os ou excluindo-os de sua vida. Enfim, nossa cultura vivencia o consumo como forma privilegiada de, por meio dele, traduzir afetos, desejos e relações sociais, elaborando uma visão de mundo. A etnografia é um método privilegiado de análise cultural e, por isso, desempenha um papel-chave no entendimento dos sistemas simbólicos que articulam os objetos de consumo e a vida cotidiana dos atores sociais na cultura contemporânea.

\section{REFERÊNCIAS}

BALLVÉ, F. A criança e a experiência do consumo. Dissertação de Mestrado. Rio de Janeiro: Coppead/UFRJ, 2000.

BARROS, C. Marketing e etnografia: um levantamento em journals dos anos 80 e 90. In: ENCONTRO NACIONAL DA ASSOCIAÇÃO NACIONAL DOS PROGRAMAS DE PÓS-GRADUAÇÃO E PESQUISA EM ADMINISTRAÇÃO, 26., Salvador. Anais. Salvador: Enanpad, 2002.

BELLIA, L. O consumo dos moradores da Barra da Tijuca. Dissertação de Mestrado. Rio de Janeiro: Coppead/UFRJ, 2000.
BLAJBERG, C. Em busca de uma identidade. Dissertação de Mestrado. Rio de Janeiro: Coppead/UFRJ, 2001.

CAMPBELL, C. The Romantic Ethic and the Spirit of Modern Consumerism. Oxford: Blackwell Publishers, 1987.

CARVAlHo, C. A. Simbologia de objetos decorativos. Dissertação de Mestrado. Rio de Janeiro: Coppead/UFRJ, 1997.

CELSI, R.; ROSE, R.; LEIGH, T. An exploration of high risk leisure consumption through skydiving. Journal of Consumer Research, v. 20, n. 1, p. 1-23, Jun. 1993.

CLIFFORD, J. A experiência etnográfica: antropologia e literatura no século XX. Rio de Janeiro: Ed. UFRJ, 1998.

DAMATTA, R. A casa e a rua. São Paulo: Brasiliense, 1985.

D'ANGELO, A. Cultura e consumo: apanhado teórico e reflexões para o ensino e a pesquisa de Marketing e Administração. In: ENCONTRO NACIONAL DA ASSOCIAÇÃO NACIONAL DOS PROGRAMAS DE PÓSGRADUAÇÃO E PESQUISA EM ADMINISTRAÇÃO, 27., 2003, Atibaia. Anais. Atibaia: Enanpad, 2003.

DOUGLAS, M; ISHERWOOD, B. The World of Goods. Middlesex: Penguin, 1978.

DUMONT, L. Homo hierarchicus. Paris: Gallimard, 1972.

DURKHEIM, É. Representações individuais e representações coletivas In: Sociologia e filosofia. Rio de Janeiro: Forense, 1970.

ELLIOTT, R.; JANKEL-ELLIOTT, N. Using ethnography is strategic consumer research. Qualitative Market Research; v. 6, n. 4, p. 215-223, 2003.

FALK, P; CAMPBELL, C. The Shopping Experience. London: Sage, 1997.

FERREIRA, M. L. Reconstruindo a identidade. Dissertação de Mestrado. Rio de Janeiro: Coppead/UFRJ, 2002.

GEERTZ, C. A interpretação das culturas. Rio de Janeiro: Zahar, 1978.

GEERTZ, C. O saber local: novos ensaios em antropologia interpretativa. Petrópolis, RJ: Vozes, 1997.

GRAZIA, V.; FURLOUGH, E. The Sex of Things. California: University of California Press, 1996.

KOZINETS, R. Utopian enterprise. Journal of Consumer Research, v. 28, n. 1, p. 67-88, Jun. 2001.

KUBOTA, L. C. Consumo e ciclo de vida. Dissertação de Mestrado. Rio de Janeiro: Coppead/UFRJ, 1999.

LABOURTHE-TOLRA, P.; WARNIER, J. P. Etnologia-antropologia. Petrópolis, RJ: Vozes, 1997.

MALINOWSKI, B. Argonautas do Pacífico ocidental. São Paulo: Abril Cultural, 1984 
MARTINEZ, C. Os paradoxos do consumo. Dissertação de Mestrado. Rio de Janeiro: Coppead/UFRJ, 2002

MAUSS, M. Ensaio sobre a dádiva: forma e razão da troca nas sociedades arcaicas. In: MAUSS, M. Sociologia e antropologia. São Paulo: EPU, 1974.

MCCRACKEN, G. Culture and consumption. Indiana: Indiana University Press, 1988.

MCGRATH, M. An ethnography of a gift store. Journal of Retailing, v. 65, n. 4, p. 421-449, Winter 1989.

MILLER, D. The poverty of morality. Journal of Consumer Culture, v. 1, n. 2, p. 225-243, 2001

OSWALD, L. Culture swapping: consumption and ethnogenesis of middle-class Haitian immigrants. Journal of Consumer Research, v. 25, n. 4, p. 303-318, Mar. 1999

OUCHI, C. O global e o local na construção da identidade. Dissertação de Mestrado. Rio de Janeiro: Coppead/UFRJ, 2000.

PEIRANO, M. A favor da etnografia. Rio de Janeiro: Relume-Dumará, 1995.

ROCHA, E. Magia e capitalismo. São Paulo: Brasiliense, 1985.

ROCHA, E. A sociedade do sonho. Rio de Janeiro: Mauad, 1995.

ROCHA, E. et al. Cultura e consumo: um roteiro de estudos e pesquisas. In: ENCONTRO NACIONAL DA ASSOCIAÇÃO NACIONAL DOS PROGRAMAS DE PÓS-GRADUAÇÃO E PESQUISA EM ADMINISTRAÇÃO, 23., Foz do Iguaçu. Anais. Foz do Iguaçu: Enanpad, 1999.

ROSSI, C. A. V.; HOR-MEYLL, L. F. Explorando novas trilhas na pesquisa do consumidor. In: ENCONTRO NACIONAL DA ASSOCIAÇÃO NACIONAL DOS PROGRAMAS DE PÓS-GRADUAÇÃO E PESQUISA EM ADMINISTRAÇÃO, 25., Campinas. Anais. Campinas: Enanpad, 2001.
SAHLINS, M. Cultura e razão prática. Rio de Janeiro: Zahar, 1979.

SCHOUTEN, J. Selves in transition: symbolic consumption in personal. Rites of passage and identity reconstruction. Journal of Consumer Research, v. 17, n. 4 , p. $412-425,1991$.

SCHOUTEN, J.; MCALEXANDER, J. Subcultures of consumption. Journal of Consumer Research, v. 22, n. 1, p. 43-61, Jun. 1995.

SHERRY JR., J. Observations on Marketing and Consumption: An Anthropological Note. Provo, UT: Advances in Consumer Research, 1989. p. $555-556$.

SHERRY JR., J. Contemporary Marketing and Consumer Behavior. London: Sage, 1995

SILVEIRA, T. Luxo, moda e marca. Dissertação de Mestrado. Rio de Janeiro: Coppead/UFRJ, 2002.

SOARES, J. A singularidade invisivel. Dissertação de Mestrado. Rio de Janeiro: Coppead/UFRJ, 2002.

VEBLEN, T. A teoria da classe ociosa. São Paulo: Pioneira, 1965.

VELLIQUETTE, A.; MURRAY, J.; CREYER, E. The tattoo renaissance: an ethnographic account of symbolic consumer behavior. Advances in Consumer Research, 1998.

WALLENDORF, M.; ARNOULD, E. We gather together. Journal of Consumer Research, v. 18, n. 1, p. 13-31,. 1991.

WALTHER, L. Imagem, luxo e dilema. Dissertação de Mestrado. Rio de Janeiro: Coppead/UFRJ, 2002.

WHYTE, W. F. Sociedade de esquina. Rio de Janeiro: Jorge Zahar, 2005.

Artigo recebido em 15.04.2005. Aprovado em 11.07.2006.

\section{Everardo Rocha}

Professor Associado do departamento de Comunicação Social pela PUC-Rio e Professor Colaborador do COPPEAD/UFRJ. Doutor em Antropologia Social pelo Museu Nacional da UFRJ.

Interesses de pesquisa nas áreas de antropologia do consumo.

E-mail: everardo@pobox.com

Endereço: Rua Marquês de São Vicente, 225, Gávea, Rio de Janeiro - RJ, 22453-900.

\section{Carla Barros}

Professora da ESPM-RJ e PUC-Rio. Doutoranda em Administração de Empresas pelo COPPEAD/UFRJ.

Interesses de pesquisa nas áreas de antropologia do consumo e marketing.

E-mail: carlapbarros@gmail.com

Endereço: Rua Marquês de São Vicente, 225, Gávea, Rio de Janeiro - RJ, 22453-900. 